\title{
General-purpose blade infrastructure for configurable system architectures
}

\author{
Kevin Leigh • Parthasarathy Ranganathan • \\ Jaspal Subhlok
}

Published online: 6 September 2007

(C) Springer Science+Business Media, LLC 2007

\section{Erratum to Distrib Parallel Databases \\ DOI: $10.1007 / s 10619-007-7010-3$}

In the original article, published in Volume 21, Numbers 2/3, Fig. 10 was shown incorrectly. The following is the correct figure.

The online version of the original article can be found under doi:10.1007/s10619-007-7010-3.

\section{K. Leigh $(\bowtie)$}

Hewlett-Packard (HP), 20555 SH249, Houston, TX 77070, USA

e-mail: kevin.leigh@hp.com

\section{P. Ranganathan}

Hewlett-Packard (HP), 1501 Page Mill, MS 1177, Palo Alto, CA 94304, USA

e-mail: partha.ranganathan@hp.com

\section{J. Subhlok}

University of Houston (UH), Houston, TX, USA

e-mail: jaspal@cs.uh.edu 


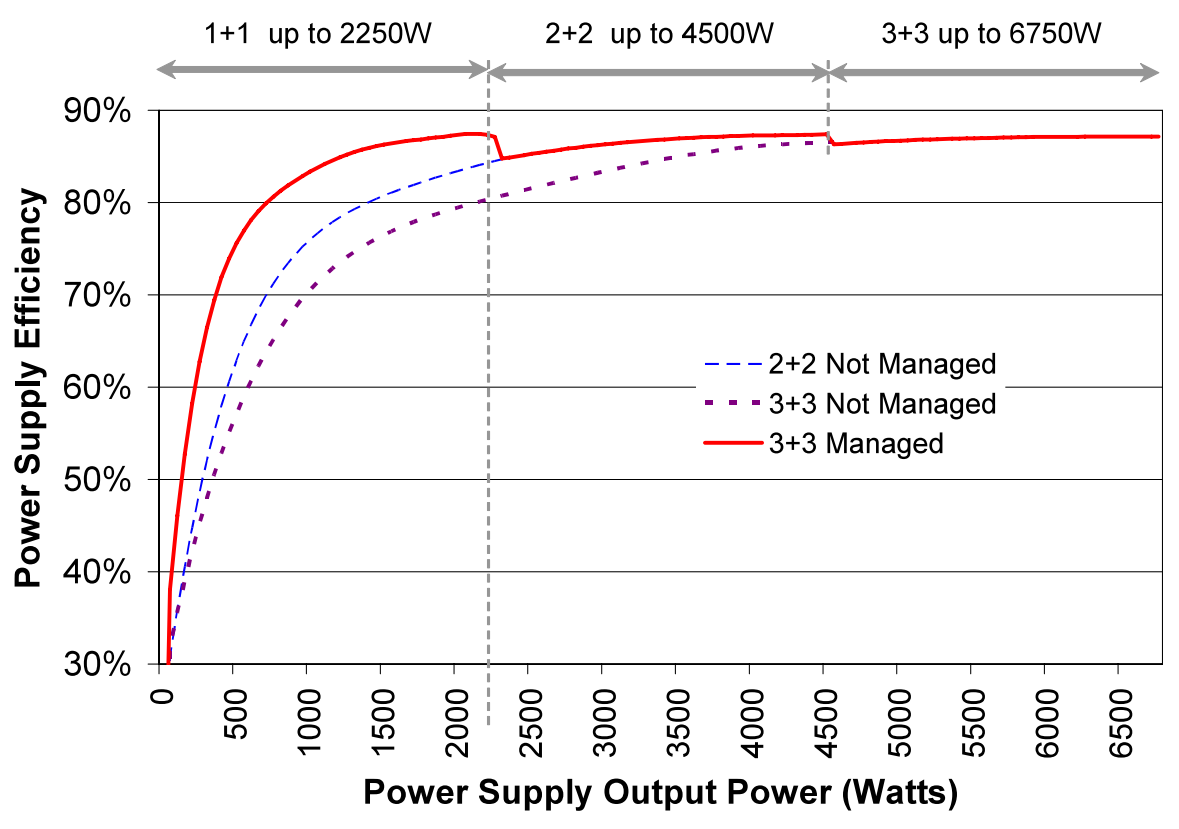

Fig. 10 Power supply efficiencies vs. load 